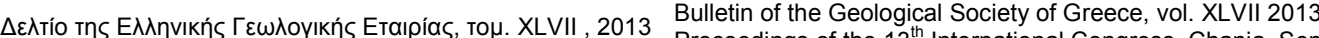

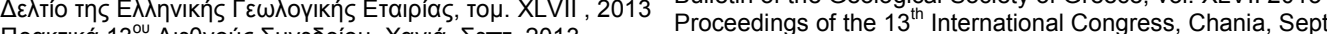

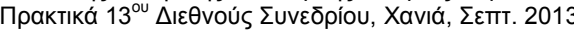
2013

\title{
EARTHQUAKE RELOCATION FOR NORTHWESTERN GREECE USING 3D CRUSTAL MODEL; METHOD COMPARISON AND SEISMOTECTONIC INTERPRETATION
}

\author{
Stavroulopoulou O. ${ }^{1}$, Sokos E. ${ }^{1}$, Martakis N. ${ }^{2}$ and Tselentis G-A. ${ }^{1}$ \\ ${ }^{1}$ University of Patras, Faculty of Geology, Seismological Laboratory, ostavrol@upatras.gr, \\ esokos@upatras.gr,tselenti@upatras.gr \\ ${ }^{2}$ LandTechEnterprises,nmartakis@landtechsa.com
}

\begin{abstract}
A dense microseismic network was installed in Northwestern Greece for a period of eleven months. A total of 1368 events were recorded and located using a $1 D$ model. These events were also used to derive a $3 D$ velocity model for the area. This work presents results from further processing of the data using (a) simple location method of events in a $1 D$ medium through Hypo 71 standard procedure; (b) location via the probabilistic, non-linear earthquake location method in $3 D$ medium; (c) relocation of the events using the Double - Difference method in $1 D$ medium; and (d) the same relocation procedure invoking $3 D$ medium. The application of different location methodologies results in slightly different locations, which are evaluated using as criterion the compactness of hypocenter distribution. The three point method was used in order to derive linear characteristics from the hypocenter distribution and the final results were compared against the focal mechanisms of the events as computed using the polarity method and the $3 D$ velocity model. The combination of accurately computed hypocenters and focal mechanisms provides important information for the seismotectonics of Epirus.
\end{abstract}

Key words: Epirus, Focal mechanisms, Non Linear Location, Three-point method.

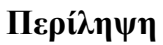

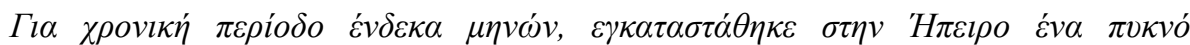

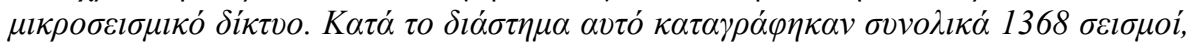

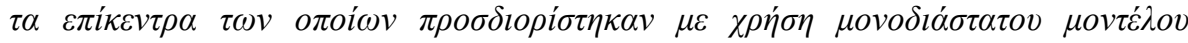

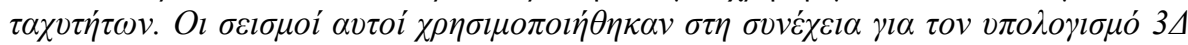

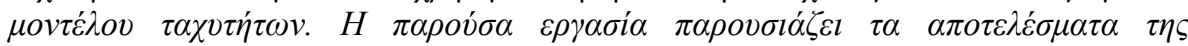

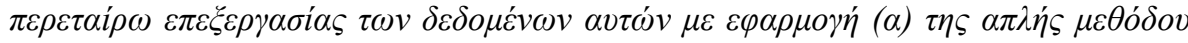

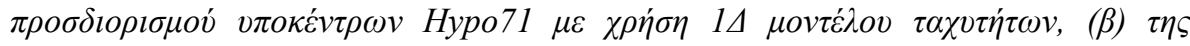

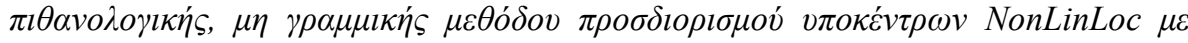

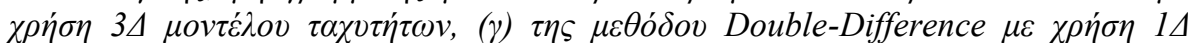

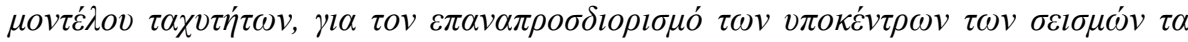

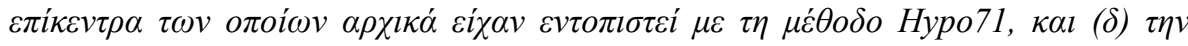

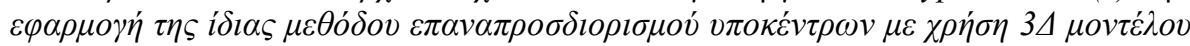

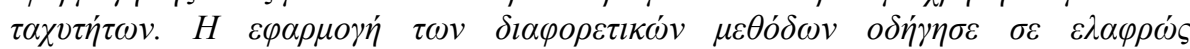

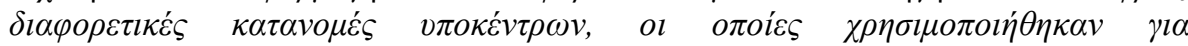

$\underline{\text { XLVII, No } 3-1269}$ 


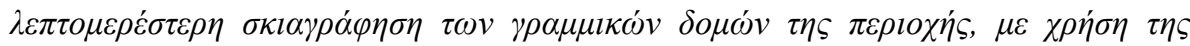

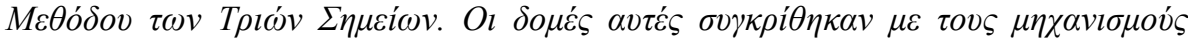

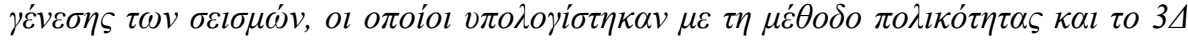

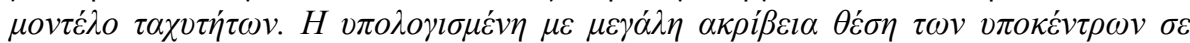

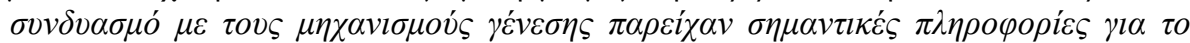

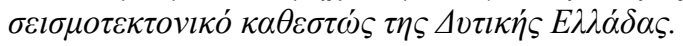

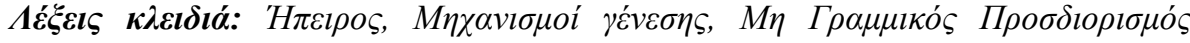

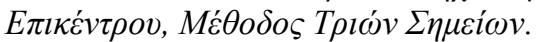

\section{Introduction}

Seismic event location and relocation is a critical task in seismology and can be accomplished with various methodologies. This study uses high quality data to evaluate four methods on location/relocation. The methods are, (a) simple location method of events in a 1D medium through Hypo71 (Lee and Lahr, 1975), (Lee and Valdes, 1985), standard procedure, (b) location via the probabilistic, non-linear earthquake location method in 3D medium (Lomax et al., 2000), (c) relocation of the events whose epicenters were initially located with Hypo 71 within the area defined by the microseismic network, using the Double - Difference method in 1D medium (Waldhauser and Ellsworth, 2000), (Waldhauser, 2001) and (d) the same relocation procedure invoking 3D medium. Data were recorded in the Epirus region, northwestern Greece, using a dense seismic network (Martakis, 2003). This unique dataset offers an opportunity to test the performance of location/relocation algorithms especially in the case of 3D velocity model use. As expected the different methodologies provide different results, and we estimate their performance based on the linear characteristics of the located/relocated seismicity. We present here results from location/relocation in $1 \mathrm{D}$ and 3D medium and discuss the results in relation to the region's seismotectonics.

Epirus lies between the Pindus Mountains and the Ionian Sea and has been the subject of several detailed geodynamic studies, as it is considered an area of particular interest in terms of its geodynamics. Geologically belongs to External Hellenides which are formed by three isopic zones (Brunn, 1956; Aubouin 1959; Bernoulli \& Laubsher. 1972; Jacobshagen, 1986), namely the Pindos, Gavrovo and Ionian zone. Starting from the eastern end, the Pindos zone is thrusted on the Gavrovo zone and the latter on the Ionian zone (Avramidis et al., 2000).

Previous microearthquake studies in Epirus performed by Kiratzi et al., (1987), Waters, (1994) and Hatzfeld et al., (1995), propose an ENE-WSW shortening, which is in agreement with the continental convergence west of Corfu and a NNW extension, further east, close to the Pindos foothills. Geomorphological work performed by King et al., (1983) using boundary-element modelling, identified a substantial left lateral strike-slip component in addition to the compressional motion. Furthermore, geological and geomorphological research which was conducted by IGSR and IFP, (1966) and King et al., (1993) as well as crustal deformation studying of the Aegean area by Papazachos and Kiratzi, (1996), implied similar results.

From the geodynamical point of view, the study area is in a strategic position where the extensional Inner Aegean regime switches to the compressional outer Aegean. Studies of the focal mechanisms from earthquakes within the area, have shown that the tectonic regime of the area varies from thrust and strike slip to normal (Mercier et al., 1972; King et al., 1983; Doutsos et al., 1987; Underhill, 1989; Waters, 1994; Hatzfeld et al., 1995).

The E-W shortening generates thrust belts that trend N-NW (Taymaz et al., 1991) and are cut by almost perpendicular strike slip or normal faults. Hatzfeld et al., (1995), assert that the jump of active thrusting from the Pindos to the Ionian zone, which continues to present time, causes the compressional regime in Epirus.

XLVII, No 3 - 1270 
Tselentis et al., (2006), based on the seismicity distribution and the stress-inversion results, concluded that the existence of evaporites have played an important role in the change of the stress regime, just at the internal Ionian thrust, which seems to be the boundary between the transtensional regime in the east to transpressional to the west.

In this article we extent the work of Tselentis et al., (2006), by applying four different location/relocation methodologies to high-quality seismological data for the area of Epirus. The application of different location methodologies results in slightly different locations. The compactness of hypocenter distribution computed from each method was used as the criterion to evaluate the location accuracy. Furthermore, it provides important information regarding the ability of the hypocenter distribution to delineate linear structures. Finally, we compare the obtained results with the known active structures within the study area.

\section{Seismograph Network and Data}

The data analyzed in this study were recorded during a 12-month period (August 1998 - June 1999) by a dense microseismic network of 44 portable seismographs which was installed in the study area by the Seismological Laboratory, University of Patras, Greece.

The network consisted of 44 three component seismic stations. Thirty eight stations were Earthdata PR2400-type 24bit seismographs and SIG SR2 short period type seismometers. They were installed in boreholes of $15 \mathrm{~m}$ depth; the remaining 6 stations consisted of Teledyne PDAS100- type 16bit recorders and of 3 Teledyne S13 short period seismometers. The recording was continuous at $100 \mathrm{samples} / \mathrm{sec}$. Recorded data were collected every 15 days and stored in 80 $\mathrm{Gb}$ hard discs. For time synchronization each station was equipped with a high-precision Magellan-type GPS, with measurement error of less than $20 \mathrm{~m}$. The location of the stations was based on the criteria indicated by Lee and Stewart, (1981). They determine the required minimum number of stations, the azimuthal gap and the relationship between the focal depth and the epicentral distance from the closest station.

Event selection and time correlation of the identified events was performed by custom-developed software, based on the STA/LTA (short-term average/long-term average) algorithm and a minimum number of 8 stations as a criterion. Data processing was performed using Sismwin software (Xanalatos and Tselentis, 1997).

During the aforementioned 12-month operation 1368 earthquakes were recorded, with duration magnitude ranging from 1.11 to 4.69 and focal depths ranging from a few hundred meters to $46 \mathrm{~km}$; the majority was in the $0-10 \mathrm{~km}$ range.

\section{Methodology}

\subsection{Location 1D (HYPO71)}

The initial location of the 1368 events in 1D medium was performed using the standard location program HYPO71 (Lee and Lahr, 1975; Lee and Valdes, 1985). The velocity model adopted for this procedure was calculated by 1D tomographic inversion performed by Martakis, (2003) in the study area.

\subsection{Location 3D (NLLoc)}

To improve the initial location results, the NonLinLoc, probabilistic, non-linear earthquake location method in 3D medium (Lomax et al., 2000), was applied to the same seismological data. The velocity model which was used for this procedure was derived by $3 \mathrm{D}$ tomographic inversion performed by Martakis, (2003) in the study area. The earthquake location algorithm implemented in the program NLLoc follows the probabilistic formulation of inversion presented in Tarantola and Valette, (1982) and Tarantola, (1987), which produces comprehensive uncertainty and 
resolution information represented by a probability density function (PDF) over the unknown hypocentral parameters. The errors in the observations (phase time picks) and in the forward problem (travel-time calculation) are assumed to be Gaussian. This assumption allows the direct, analytic calculation of a maximum likelihood origin time given the observed arrival times and the calculated travel times between the observing stations and a point in XYZ space. For accurate, efficient and complete mapping of earthquake location probability density functions (PDFs) in 3D space, the oct-tree importance sampling algorithm was chosen (Lomax and Curtis, 2001). This method is faster than grid-search (factor 1/100) and uses very few parameters (initial grid size, number of samples).

Figure 1shows the epicentre distribution and the cross-section across the study area of the located events with the NonLinLoc method in 3D medium. The hypocenter determination is similar to HYPO71, as expected since the events are well recorded, but the non linear location provides a better view of the location errors.

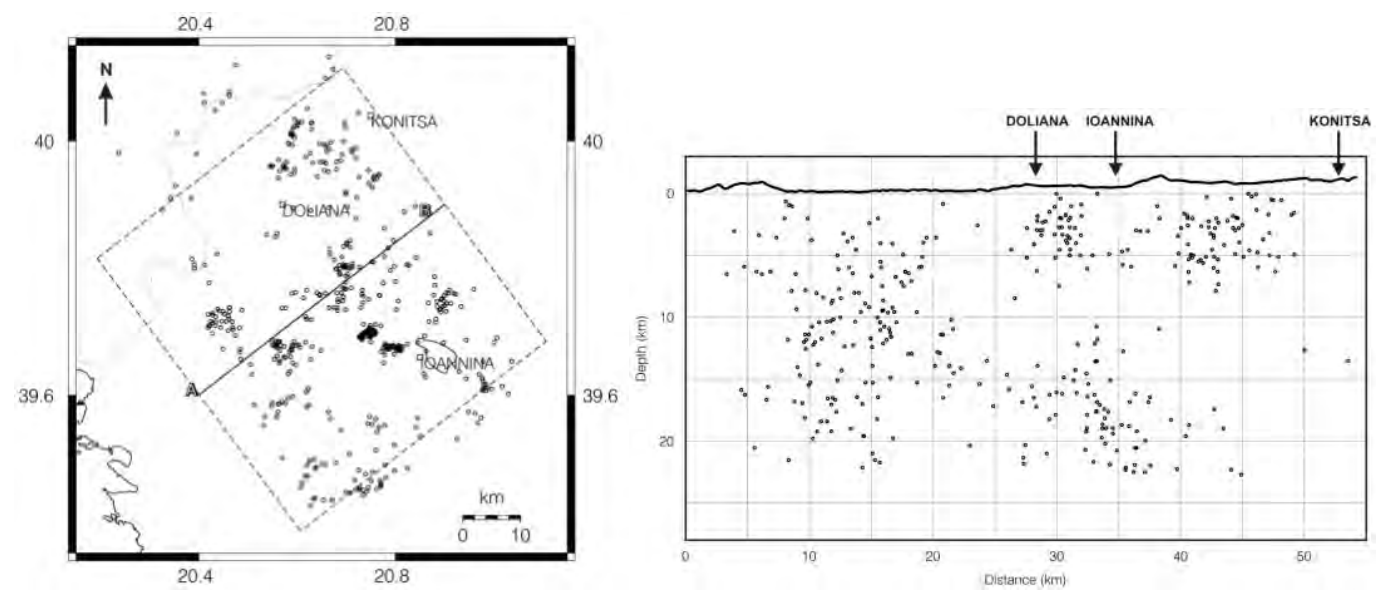

Figure 1 - The epicentre distribution (left) and the cross-section across the study area (right) of the located events with the NonLinLoc method in 3D medium.

\subsection{Relocation 1D (HypoDD 1.0)}

The events whose epicenters were initially located with HYPO71 standard procedure within the area defined by the microseismic network, were relocated using the Double - Difference method in 1D medium (Waldhauser and Ellsworth, 2000), as implemented in HypoDD 1.0 program (Waldhauser, 2001), to improve relative location accuracy by removing effects due to un-modelled velocity changes. The velocity model which was used for this procedure was the same that was used for the location in 1D medium. Using this method, residuals between observed and theoretical travel-time differences (or double-differences) were minimized for pairs of earthquakes at each station while linking together all observed event-station pairs. A least-squares solution is found by iteratively adjusting the vector difference between hypocentral pairs. For the relocation procedure all 452 events which had initially been located inside the microseismic network were selected. A total of 271 of them formed 10 clusters including more than 10 events each, with maximum hypocentral separation between the event-pairs, $2 \mathrm{~km}$. These were chosen to be further analysed below.

Figure 2 shows the epicentre distribution (left) and the cross-section across the study area (right) of the relocated events with the HypoDD method in 1D medium. As expected the hypocenter distribution is more compact, since events collapse to clusters and thus linear features were revealed. 

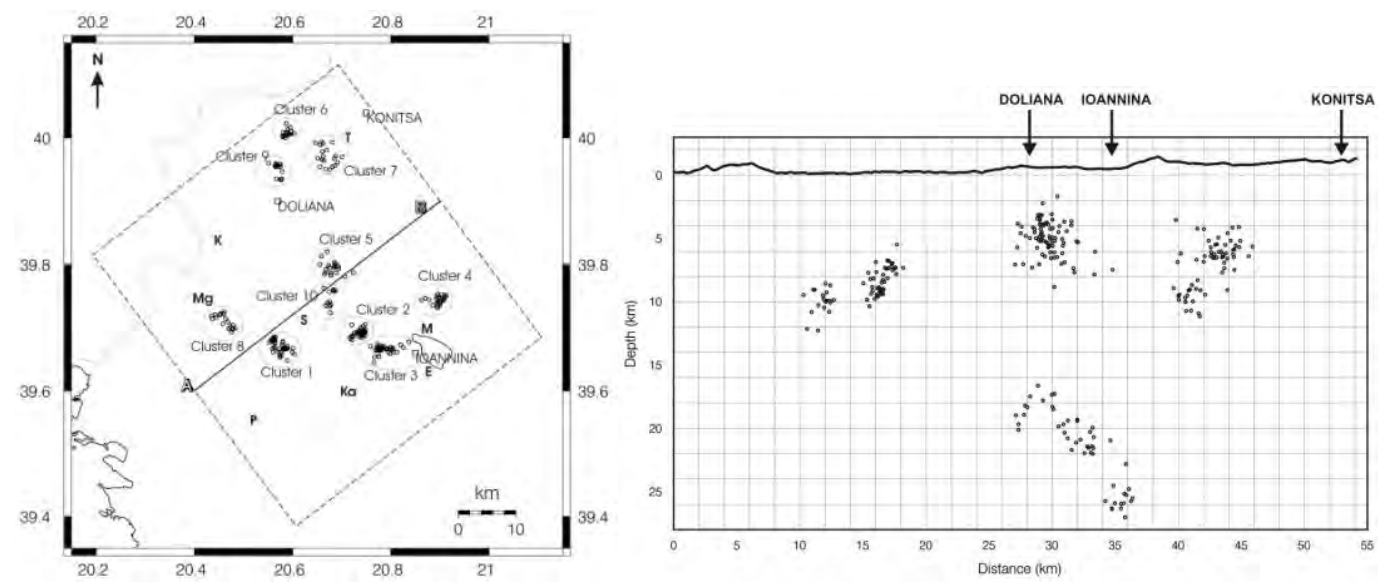

Figure 2 - The epicentre distribution (left) and the cross-section across the study area (right) of the relocated events with the HypoDD method in 1D medium. P, Paramythia; Mg, Mourgana mountain; K, Kourendon; S, Soulopoulo; Ka, Kassidiares; E, Evaporite outcrop; M, Mitsikeli mountain; T, Tymfi mountain.

\subsection{Relocation 3D (HypoDD 2.1)}

For further enhancement of the hypocentral parameters, the relocation procedure was further applied to the seismological data, invoking 3D medium using the Double - Difference method in 3D medium (Waldhauser and Ellsworth, 2000), as implemented in HypoDD 2.1 program (Waldhauser, 2001). The velocity model which was used for this procedure was the same that was used for the location in $3 \mathrm{D}$ medium, as described above. This is a recently proposed enhancement of HypoDD algorithm and the current application is one of the first worldwide, thus it serves as a benchmark of the algorithms performance. HypoDD relocation in $3 \mathrm{D}$ medium produces slightly different results if we compare with the relocation in 1D medium, this is probably due to method's independence of the crustal model or in the data quality.

\section{Focal Mechanisms}

The fault-plane solutions were determined using the FPFIT program (Reasenberg and Oppenheimer, 1985), a grid search routine that minimizes the misfit between nodal planes and observed first-motion data. For this procedure, the azimuth and the angle of incidence of the 271 events included into the 10 clusters computed by the HypoDD relocation method were used. The minimum number of $\mathrm{P}$-wave first-arrival observations was 10 . More than $90 \%$ of the solutions were unique. From the events with multiple solutions we selected those with the highest quality, as estimated from the uncertainty measurements determined by FPFIT. The nodal planes are wellconstrained, with mean misfit function $F_{j}$, equal to 0.11 , mean STDR equal to 0.6 and errors in strike, dip and rake $(\triangle \mathrm{STR}, \triangle \mathrm{DIP}, \triangle \mathrm{RAK})$ smaller than $10^{\circ}$. The focal mechanisms derived from this procedure, is in agreement with the previous observations within the area, as normal, reverse, srike-slip, and oblique surface structures were identified.

In the following paragraphs we discuss in detail the results obtained per cluster. We are mainly interested in the geometrical characteristics of the clusters and their connection with the focal mechanisms in order to derive results about the seismic sources involved. To define more clearly the geometry of the clusters, the Three-Point Method (Fehler et al., 1987) was applied to the relocated events. It consists in calculating, the poles of the planes that pass through each combination of three hypocenters and then, the pole density for the elements of equivalent area that form the lower hemisphere of a stereographic projection. If the pole density distribution has a clear maximum, it defines the geometry of the multiplet, that is, of its associated plane. Instead of calculating the plane's pole we calculate here the dip direction of the planes of each cluster and

$\underline{\text { XLVII, No } 3-1273}$ 
check if it is in agreement with the observed directions indicated by the fault plane solutions as they were described above. (Figures 3, 4, 5)

Cluster 1 is located at the SE corner of the study area, close to Soulopoulo (Figure 2) and contains 54 relocated hypocenters with depth range of 5 to $12 \mathrm{~km}$. The focal mechanisms vary from strike slip and normal for most of the earthquakes, which changes to thrust along NW-SE direction for some earthquakes. This observation agrees with the previous studies in the area performed by IGSR and IFP, (1966); King et al., (1993); Hatzfeld et al., (1995) and Tselentis et al., (2006) who mapped normal and oblique-normal focal mechanisms which became pure strike-slip and even the reverse for some earthquakes. According to them, the variety of faulting type implies the existence of two groups of faults, a group of oblique to normal faults that trend N-NW-SE and a group of almost vertical reverse faults of N-S trend. The reverse fault could be the Kourenton fault (Figure 2), which has been described as backthrust by IGSR and IFP, (1966).

Figure 3 shows the epicentre distribution (left), the cross-section across the cluster area (middle) and the orientations of faults (dip-direction) on equal-area projection (right), of the relocated events. The WSW dip of the cluster can be clearly observed. This suggests that this cluster is connected to a back thrust fault, most probably the Kourenton fault.
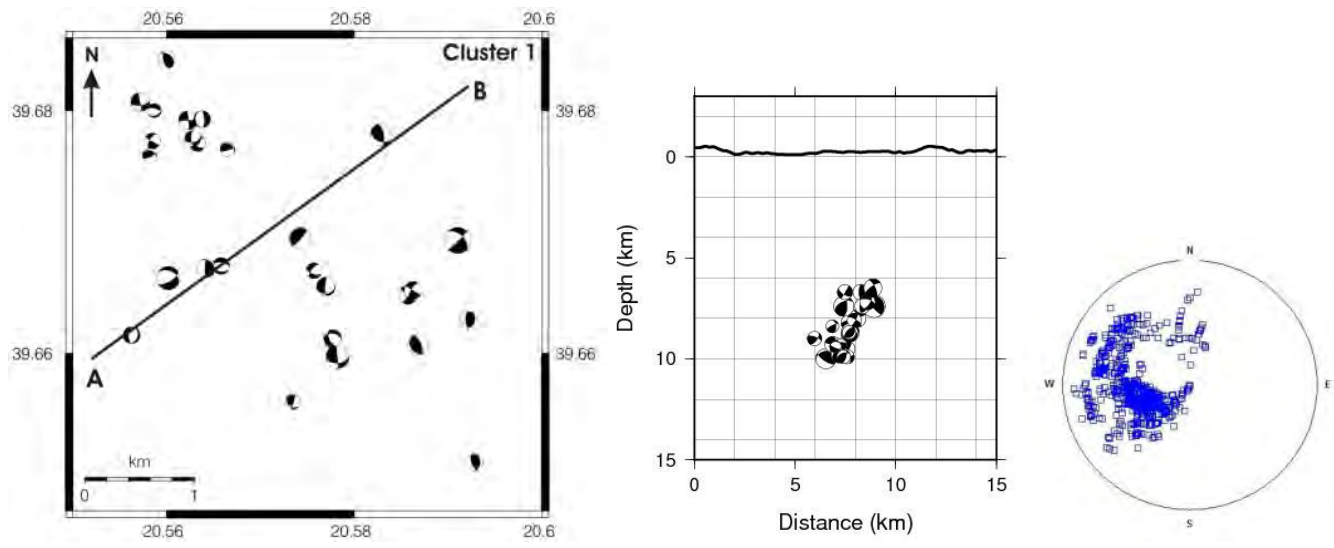

Figure 3 - The epicentre distribution (left), the cross-section across the cluster 1 area (middle) and the orientations of faults on equal-area projection (right), of the relocated events.

Cluster 2 and cluster 3 lie west of lake Pamvotis and contain 46 and 39 relocated hypocenters respectively. The majority of earthquakes occur at shallow depths up to $5 \mathrm{~km}$ with just a few deeper events limited at $10 \mathrm{~km}$. This area between Mitsikeli (M) and Kourenton (K) thrust (Figure 2) was referred by King et al., (1993) as Ioannina basin. Tselentis et al., (2006), found normal focal mechanisms in this area and related them with a set of conjugate normal faults, structures that can develop on top of evaporite domes. Also, they attributed the absence of seismicity below the depth of $5 \mathrm{~km}$, to the existence of a large evaporite body close to the surface which extends to the north. This idea was corroborate by the presence of an evaporite outcrop (Figure 2) close to the two clusters and by additional information from geophysical and geological data (IGMR, 1967). The fault plane solutions derived here for these earthquakes show pure normal and strike-slip faults which are bounded at the north part of the area by a few reverse faults with E-W strike. The depth of the earthquakes increases to the NE direction for both clusters. These results are in good agreement with Tselentis et al., (2006) and support further the idea of normal faulting associated with an evaporite dome (Figure 2) very close to the Ioannina basin surface.

Cluster 4 extends east of the mountain Mitsikeli (Figure 2) and consists of 24 relocated events with depth range of 2 to $12 \mathrm{~km}$. A variety of focal mechanisms can be observed from strike slip and normal faulting for the shallower events, to thrust faulting for the deeper ones. More specifically,

$\underline{\text { XLVII, No } 3-1274}$ 
strike slip structures are detected at the NE part of the cluster area, which are cut towards the NS direction by normal faults. These results agree with the fault plane solution proposed by Martakis, (2003) and with the extension referred by Papazachos and Kiratzi, (1996) for this area. At the SW part of the area the hypocenters become deeper and the focal mechanisms denote thrust.

Figure 4 shows the epicentre distribution (left), the cross-section across the cluster area (middle) and the orientations of faults (dip-direction) on equal-area projection (right), of the relocated events. High inclination of the faults towards a mean west direction can be observed.
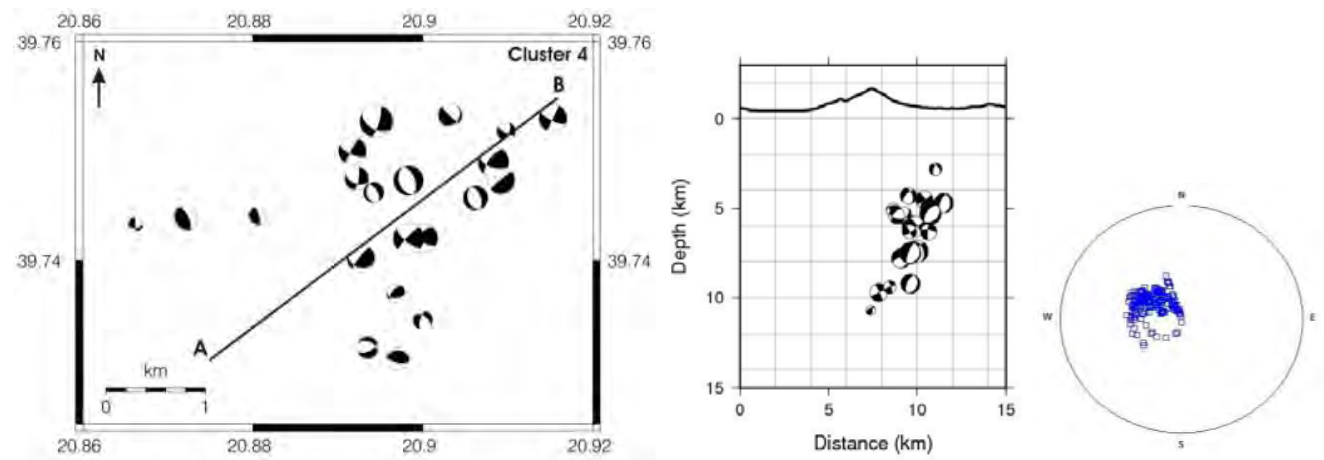

Figure 4 - The epicentre distribution (left) and the cross-section across the cluster 4 area (middle) and the orientations of faults on equal-area projection (right), of the relocated events.

In the centre of the study area, east of Soulopoulo (S) and the Kasidiares (K) thrust (Figure 2) two hypocenter clusters are located with focal depths significantly different from the average depth of the study area. These are cluster 5 which contains 21 events and its depths range from 18 to $24 \mathrm{~km}$ and a smaller one, cluster 10 which contains 13 events and its depths range from 16 to $20 \mathrm{~km}$. Similar deepening of the hypocenters was observed by Hatzfeld et al., (1995) and Tselentis et al., (2006). The fault plane solutions observed for these two clusters show pure reverse faulting, with a few, scattered, oblique-normal focal mechanisms. Furthermore, in cluster 5 a deepening of the hypocenters towards the NE direction occurs. These events are connected with a deep thrust zone that dips to the east and this is probably the middle Ionian thrust or some other blind thrust.

Figure 5 shows the epicentre distribution (left), the cross-section across the cluster 5 area (middle) and the orientations of faults (dip-direction) on equal-area projection (right), of the relocated events. The dip direction of the faults towards the ENE direction can be observed.
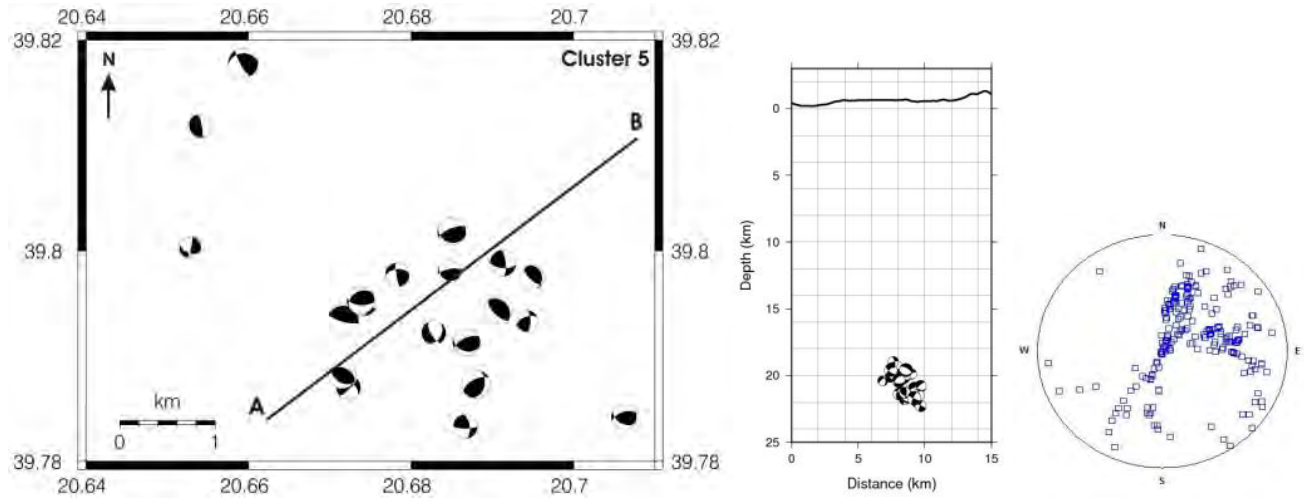

Figure 5 - The epicentre distribution (left) and the cross-section across the cluster 5 area (middle) and the orientations of faults on equal-area projection (right), of the relocated events.

$\underline{\text { XLVII, No } 3-1275}$ 
Cluster 6 is the northeast group of 20 relocated events, close to the Greek-Albanian border. Even though hypocentral depths range from 4 to $12 \mathrm{~km}$, most of the relocated events are concentrated around $10 \mathrm{~km}$. Fault plane solutions are normal and oblique-normal, which is in agreement with IGSR and IFP, (1966) reference. This cluster is probably connected with a normal oblique fault, following the general NE-SW trending of the Konitsa normal fault system (Galanakis et al., 2007) (Figure 2).

Cluster 7 contains 20 shallow events located in the area of the mountain Timfi (Figure 2). Their depths range from 2 to $10 \mathrm{~km}$. Most of the fault plane solutions for these earthquakes are of normal and oblique normal type. These can be explained as a result of the extension which is taking place in this area (Papazachos and Kiratzi, 1996) and (Doutsos and Koukouvelas, 1998). Additional information comes from Tselentis et al., (2006) seismotectonic study in Epirus, who detected NNE strike-slip focal mechanisms and sometimes clear N-S mechanisms.

Cluster 8 is located at the eastern part of the study area which is referred to as the Paramythia (P)Mourgana (Mg) area (Figure 2), where the main observed structure is thrust with NW-SE epicentre distribution. This is probably connected with the middle Ionian thrust further west, described by IGSR and IFP, (1966). In the same direction there are also a few strike-slip and oblique-normal focal mechanisms. The fault plane solution variation agrees with observations in the same area by Tselentis et al., (2006). This cluster contains 19 relocated hypocenters with focal depths around $10 \mathrm{~km}$ while a few scattered ones are located at depths of 6 to $14 \mathrm{~km}$

Cluster 9 is a small cluster of 15 events extended from 24 to $35 \mathrm{~km}$ depth at the Doliana basin (King et al., 1993), (Figure 2). The fault plane solutions derived for these events show thrust and oblique thrust faulting with a mean strike at NW-SE direction. Hypocenter distribution suggests that cluster dips to the east. These structures could be connected with the middle Ionian thrust (IGSR and IFP, 1966) or another major thrust west of Doliana basin (e.g. the northern part of Kasidiares thrust) (Figure 2).

\section{Results}

In this paper we make use of a high quality seismic dataset in order to test a number of location/relocation methods and derive accurate location of seismicity in Epirus. In detail we investigate the effect of 3D crustal model in earthquake location/relocation using the most recently proposed methods in this area i.e. non-linear location in 3D medium (Lomax et al., 2000) and relocation in 3D medium (Waldhauser, 2001). Our results, based on a very good dataset, suggest that the hypocenters obtained by $3 \mathrm{D}$ non linear location are similar to 1D location methods.

Nevertheless, the associated location errors are defined in a transparent way in the non linear location method and this is a major advantage. Similarly the relocation by HypoDD in 3D medium didn't provide significantly better results in comparison to standard HypoDD in 1D medium. This was in some extend expected since the relocation methodology itself doesn't depend on crustal model accuracy. Since all the methods were tested in a high quality dataset we cannot rule out a bias by the data quality i.e. we don't suggest that similar results can be obtained using a lower quality dataset.

Results from the seismicity relocation procedure and focal mechanisms obtained using the relocated hypocenters and the first polarity method were used to derive results about the seismotectonic environment in Epirus. In general results are in agreement with Tselentis et al., (2006), although a more detailed image is provided here. The active structures in the study area agree with a thrust belt zone at the west, combined with an extensional regime at the eastern end. The presence of evaporite bodies is clearly defined from seismic data in good connection to geological findings. 


\section{Acknowledgments}

All the figures were produced with the GMT software package (Wessel and Smith, 1991). The first author thanks Vasilis N. Nikolaidis and Paraskevas Paraskevopoulos for their assistance in software development and use.

\section{References}

Aubouin J. 1959. Contribution a l'etude geologique de la Greece, septentrionale, les confins de l'Epire et de la Thessalie, Ann. Geol. Pays. Hellen 10, 1-483.

Avramidis P., Zelilidis A. and Kontopoulos N. 2000. Thrust dissection control of deep-water clastic dispersal patterns in the Klematia - Paramythia foreland basin, western Greece, Geol. Mag. 137, no. 6, 667-685.

Bernoulli D. and Laubscher H. 1972. The palinspastic problem of the Hellenides, Eel. geol. Helv., 65, 107-118.

Brunn J.H. 1956. Contribution a l'etude geologique du Pinde Septentrional et d'une partie de la Macedonie occidentale. Annales Geologique des pays Helleniques, Vol. VII.

Doutsos T. and Koukouvelas I. 1998. Fractal analysis of normal faults in northwestern Aegean area, J. Geodyn. 26, 197-216.

Doutsos T., Kontopoulos N. and Fridas D. 1987. Neotectonic evolution of northwestern continental Greece, Basin Res. 1, 177-190.

Fehler M., House L. and Kaieda H. 1987. Determining planes along which earthquakes occur: method and application to earthquakes accompanying hydraulic fracturing, J. geophys. Res., 92(B9), 9407-9414.

Galanakis D., Paschos P., Rondoyanni T. and Georgiou C. 2007. Neotectonic Activity of Konitsa Area and the 1996 Earthquakes, Hellenic Journal of Geosciences, vol. 42, 57-64.

Hatzfeld D., Kassaras L., Panagiotopoulos D., Amorese D., Makropoulos K., Karakaisis G. and Coutand O. 1995. Microseismicity and strain pattern in northwestern Greece, Tectonics 14, $773-785$

Institute of Geology and Mineral Resources (IGMR), 1967. Geological map of Greece, Ioannina and Klematia sheet (1:50,000), Athens, Greece.

Institute for Geology Subsurface Research of Greece and Institute Francais de Petrole (IGSR and IFP), 1966. Etude geologique de l'Epire, Paris, Technip, 306 pp.

Jacobshagen V. 1986. Geologie von Griechenland, Beiträge Zur Regionalen Geologie der Erde, 19, Berlin.

King G., Tselentis A., Gomberg J., Molnar P., Roecker S., Sinvhal H., Soufleris C. and Stock J. 1983. Microearthquake seismicity and active tectonics of northwestern Greece, Earth Planet Sc. Lett. 66, 279-288.

King G., Sturdy D., and Whitney J. 1993. The landscape geometry and active tectonics of the northwest Greece, Geol. Soc. Am. Bull. 105, 137-161.

Kiratzi A., Papadimitriou E., and Papazachos B. C. 1987. A microearthquake survey in the Steno dam site in northwestern Greece, Ann. Geophys. 592, 161-166.

Lee W.H.K. and Lahr J.C. 1975. HYPO71 (Revised): A computer program for determining hypocenter, magnitude, and first motion pattern of local earthquakes, U.S. Geol. Surv. OpenFile Rept. OF 85-749.

Lee W.H.K., and Stewart S. W. 1981. Principles and Applications of Microearthquake Networks, Adv. Geophys., Supplement No. 2, Academic Press, New York, 293 pp.

Lee W.H.K. and Valdes C. M. 1985. HYPO71PC A personal computer version of the HYPO71 earthquake location program, U.S. Geol. Surv. Open-File Rept. OF 85-749.

Lomax A., Virieux J., Volant P. and Berge C. 2000. Probabilistic earthquake location in 3D and layered models: Introduction of a Metropolis-Gibbs method and comparison with linear locations, In: Advances in Seismic Event Location Thurber, C.H., and N. Rabinowitz (eds.), Kluwer, Amsterdam, 101-134.

XLVII. No $3-1277$ 
Lomax A. and Curtis A. 2001. Fast, probabilistic earthquake location in 3D models using oct-tree importance sampling, European Geophysical Society, March 2001, Nice.

Martakis N. 2003. Passive seismic tomography survey in Epirus, Ph.D. thesis, University of Patras - Faculty of Geology and Geophysics - Seismological Laboratory, p. 116-126, 145, 189 (In Greek).

Mercier J., Bousquet B., Delibasis N., Drakopoulos I., Keraurden B., Lemell F., and Sorel D. 1972. Deformations en compression dans le quartinaire des ravages Ioniens. Donnes neotectoniques et seismiques, C. R. Acad. Sci. Paris 275, 2307-2310.

Papazachos C. and Kiratzi A. 1996. A detailed study of the active crustal deformation in the Aegean and surrounding area, Tectonophysics 253, 129-153.

Reasenberg P. and Oppenheimer D. 1985. FPFIT, FPPLOT and FPPAGE: Fortran computer programs for calculating and displaying earthquake fault plane solutions, U.S. Geol. Surv. Open-File Rept. OF 95-515, 24 pp.

Tarantola A. 1987. Inverse problem theory: Methods for data fitting and model parameter estimation, Elsevier, Amsterdam, 613p.

Tarantola A. and Valette B. 1982. Inverse problems = quest for information, J. Geophys., 50, 159170

Taymaz T., Jackson J. A., and McKenzie D. 1991. Active tectonics of the north and central Aegean Sea, Geophys, J. Int. 106, 433-490.

Tselentis G-A., Sokos E., Martakis N. and Serpetsidaki A. 2006. Seismicity and Seismotectonics in Epirus, Western Greece: Results from a Microearthquake Survey, Bull. Seism. Soc. Am., Vol. 96, No. 5, pp. 1706-1717.

Underhill J.R., 1989. Late Cenozoic deformation of the Hellenide foreland, western Greece, Geol. Soc. Am. Bull. 101, 613-634.

Waldhauser F. and Ellsworth W.L. 2000. A double-difference earthquake location algorithm: Method and application to the northern Hayward fault, Bull. Seism. Soc. Am., 90, 1353-1368.

Waldhauser F. 2001. HypoDD: A computer program to compute double-difference earthquake locations, U.S. Geol. Surv. open-file report, 01-113, Menlo Park, California.

Waters D. 1994. The tectonic evolution of Epirus, Northwest Greece, Ph.D. thesis, University of Cambridge, Cambridge, p. 248.

Wessel P. and Smith W. H. F. 1991. Free software helps map and display data, EOS Trans. AGU $72,441,445-446$.

Xanalatos N. and Tselentis G-A. 1997. Seismwin, An Algorithm For Processing Seismological Waveforms. Proc. Geol. Soc., Athens, 22, 235-246. 